\title{
Determining the Association Between COVID-19 Cases and Congressional District Affiliation in the United States
}

\author{
Divya Kumar \\ The Academy of Science, 42075 Academy Drive, Leesburg, Virginia 20175, USA; 812180@1cps.org
}

ABSTRACT: Understanding the association between congressional district affiliation and COVID-19 cases provides a greater insight into the public health response and helps interpret the effect political affiliation has on the ability to follow public health measures. Estimated congressional district level data for COVID-19 confirmed cases were aggregated using a dasymetric interpolation method. Affiliation was measured using election data to calculate the partisan index. Five dates with significance to the public health perspective of the COVID-19 pandemic were chosen, and COVID-19 congressional district level cases were measured two weeks prior to these dates and the subsequent two weeks. Confounders were considered to create a more accurate model because they cause a spurious association. A paired t-test supported that most of the dates did have a significance in affecting the COVID-19 case rate, and that right leaning districts respond less to those critical dates compared to left leaning districts. Left leaning districts had a higher case rate towards the beginning of the pandemic, however right leaning districts saw a larger increase in cases. This model could help predict how certain politically affiliated groups act and respond during health outbreaks and which groups have a higher chance of being infected.

KEYWORDS: Behavioral and Social Sciences; Sociology and Social Psychology; Public Policy; COVID-19.

\section{Introduction}

COVID-19 (Coronavirus disease 2019) is a newly discovered infectious disease, which emerged in China and was declared a global pandemic by the World Health Organization. As of June 8th, 2021, there have been 33.4 million confirmed coronavirus cases and 598,000 related deaths in the United States. Multiple polls and data suggest that COVID-19 is profoundly a partisan issue in the United States. Political partisanship has been steadily increasing in the United States and substantially impacts behavior and beliefs (Gollwitzer et al. 2020). ${ }^{1}$ This has completely changed the perception and response of the pandemic to be political. Numerous polls have shown that political party affiliation has an effect on support for preventative health behaviors and perception of risk for the coronavirus. A survey conducted by NBC News/Wall Street Journal found that more than $68 \%$ of democrats reported being concerned about the coronavirus compared to only $40 \%$ of republicans. ${ }^{2}$ Another poll conducted by Gallup found that republicans were significantly less likely to take COVID-19 precautionary measures such as social distancing and wearing masks. ${ }^{3}$ This partisan divide has affected perceptions of public health. A congressional district is a "a territorial division of a state from which a member of the US House of Representatives is elected" (Congressional District). ${ }^{4}$ One of the main reasons that COVID-19 cases for congressional districts are not routinely available is because congressional districts are not straight-forward aggregations of already existing geographical data, for example counties or cities. By having congressional districts statistics, it can help evaluate and monitor programs specifically. They are also helpful geographically because they have roughly similar populations. Partisan differences can be expected, not because of certain policies, but rather because of individual behaviors. As mentioned before, different political parties view the seriousness of the pandemic differently and also view the necessary precautionary measures against COVID-19 differently. This could be due to homophily or herding behaviors because those in similar groups or political parties may feel the need for sameness. Similar rhetoric of political figures and in social media can be seen by corresponding political parties, which leads to imitating the certain political party's behavior.

\section{Literature Review}

Neelon et al..$^{5}$ (2020) conducted a longitudinal analysis examining COVID-19 incidence and death rates from March 1 through September 30, 2020 for the 50 states and DC. They obtained daily COVID-19 incident case and death data from a well validated source and aggregated county data to obtain state-level data. They found that gubernatorial party affiliation did drive policy decisions and polarized the attitude towards the pandemic. DeSouza and Subramanian ${ }^{6}$ (2020) mapped COVID-19 deaths and cases across United States Congressional districts. There is an omnipresence of COVID-19 statistics at the state- and county-levels because of the importance of analysis and significance of public policy. However, a critical geographic unit for which COVID-19 mortality and case statistics have not been presented are the US congressional districts. They used county-level COVID-19 cases, deaths data, and census block data. In every county, COVID-19 cases and deaths per capita were assigned to census blocks in an unweighted manner. Then collection of block-level rates in a $\mathrm{CD}$ was summed using the weighted congressional district and census block to obtain congressional district estimates of the difference in every congressional district. 
Data can be adjusted for potential confounders chosen a priori from the US Census Bureau and the Robert Wood Johnson Foundation. Which includes state population size to compute population density, the percentage of state residents aged 65 and older, the percentage of Black and Hispanic residents, the percentage below the federal poverty line, the percentage in poor or fair health, and the number of primary care physicians per 100,000 residents (Johnson et al. 2020). ${ }^{7}$

Wang and Yang $^{8}$ (2016) inspected the performance of regularized linear mixed effect models when multiple confounding factors coexist. They found that the Sparse Linear Mixed Models under sequence method of multiple confounding factors correction performed the best consistently compared across all the other combinations. They also used two log likelihood functions, MLE and REML, which both measure the goodness of fit to a sample of data for given values of the unknown parameters and found that MLE and REML methods did not distinguish from each other. The study also suggests that concatenation is the simplest way of correcting multiple confounding factors because it maintains the intuitiveness of integrating different categories into a universal one.

Neelon et al. ${ }^{5}$ (2020) conducted statistical analysis, by fitting the Bayesian negative binomial models with daily incident cases and deaths for each state as the outcomes. They stratified states by governors' affiliation and graphed the posterior mean incidence and death rates daily for the reference covariate group, as well as the $95 \%$ posterior intervals (PIs). $\mathrm{Wei}^{9}(2021)$ analyzed the Relation Between Government Anti-Contagion Policy Severity and United States COVID-19 Epidemiological Data. Tweets were used as a way to introduce an approach to assess United States policy severity using a random forest ensemble model. Wei found a significant correlation between the state policy severity and hospitalization, death, and case rates.

Coronavirus cases in association with the percentage of political affiliation of the congressional district have not been researched yet and could be an informational insight on COVID-19 precautions. DeSouza and Subramanian ${ }^{6}$ (2020) did map coronavirus cases and deaths per congressional district, however, they did not take political affiliation into account, unlike this research. Neelon et al. ${ }^{5}$ (2020) studied the association between governor political affiliation and COVID-19 cases and deaths in the United States, this research will be similar, however, instead of looking at states and governor political affiliation, this study will be looking at congressional district and the political affiliation of those who reside in that particular congressional district. Other studies used a Bayesian negative binomial model because they did not use percentage votes, instead they used governor political affiliation, so they had a definite variable, unlike this research. This study will be using a linear mixed regression model which allows for external confounding variables and the two main variables that will not be fixed. Gollwitzer et al. ${ }^{1}$ (2020) studied the partisan difference and its effect on social distancing during the coronavirus pandemic. This study will examine confirmed COVID-19 cases instead of COVID-19 precautions like physical distancing. Wang and Yang ${ }^{8}$ (2016) studied the effectiveness of multiple confounding variables and used the method of concatenation, which is similar because this research will be incorporating multiple variables into a linear mixed regression model. However, Wang and Yang ${ }^{8}$ (2016) used their regression model as an application in biological processes, while this project will be applicable to COVID-19 congressional district level cases and political affiliation. Wei ${ }^{9}$ (2021) used policy severity as a variable, but this research will be looking at political affiliation and will only be focusing on confirmed cases, while they looked at hospitalization rates, cases, and death rates. By being able to associate confirmed COVID-19 cases and congressional districts it can provide further insight to public policy and public perception of the pandemic.

In this research, COVID-19 congressional district level cases for multiple dates will also be measured to understand how certain politically affiliated groups react to those specific changes in federal guidelines, changes in public reaction, or changes in the response to the pandemic. The dates that will be utilized to measure COVID-19 confirmed cases are April 16, 2020; July 14, 2020; November 30, 2020; January 20, 2021; and March 19, 2021. April 16, 2020 was the day that new federal government guidelines, outlining a three-phase plan to reopening the country, were first introduced. This plan included thresholds and requirements for a state to move onto the next phase. It had broad criteria but aimed to reduce COVID-19 cases and deaths. By understanding the number of cases up to this day we can measure the impact of this policy. July 7,2020 was the day that the United States infection rates reached over 3 million and it was also the day that the United States began its withdrawal from the World Health Organization. By understanding if June 7,2020 had a significance in effecting COVID-19 cases, it provides further insight into whether an increase in cases or a significant number of cases had an impact in the public's reaction. November 30, 2020 is the day after the Thanksgiving weekend, where there is data to support that there was an uncontrolled amount of travel and not following federal suggested guidelines. Many experts warned about a surge in COVID-19 cases because of Thanksgiving travel. Air travel reached over 1.2 million people the day before, despite warnings and guidelines that discourage traveling. This could help quantify who followed federal suggestions to not travel during the pandemic. January 20, 2021 is the day that the presidential administration changed, therefore many policies changed as well. One of the first executive orders signed by the new administration was a mask mandate on all federal properties. This furthers the study to measure the extent of political affiliation and its effect on COVID-19 cases because of the change in presidential party administration on this day. March 19, 2021 was the day that the United States reached the goal of administering 100 million doses of the Coronavirus vaccine. On this day, over 75 million Americans had at least one dose, while over 40 million have both doses of the vaccine. Measuring cases for this date could aid in the understanding of how the increase in vaccinations and prevention methods affects congressional district COVID-19 cases. COVID-19 confirmed cases will be measured 14 days prior to the certain date and compared to the subsequent two weeks to determine 
weeks to determine if the date had a significance in affecting COVID-19 case data. It was hypothesized that right leaning districts would have a higher COVID-19 case rate, based on the general rhetoric by specific groups surrounding the pandemic. It was also hypothesized that all the chosen dates would have significance in affecting the number of COVID-19 confirmed cases because they all had an impact in public perception. In this research, congressional district level cases will be mapped using a dasymetric interpolation method and a regression analysis will be run, with COVID-19 congressional district level cases and political affiliation as the variables.

\section{- Methods}

Congressional district level COVID-19 cases were measured using population-weighted methodology, specifically the dasymetric interpolation method that accounts for the spatial distribution. County level cases were obtained from Kaggle and census block data was retrieved from IPUMS.org. County level COVID-19 cases were first used, and then were then multiplied by the census block population in proportion to the total congressional district population. Census blocks were used as the smallest common factor between congressional districts and counties. They are the source zones and rates are disaggregated into spatial units that are common to both the source and target zone. This then led to the census block COVID-19 case rate in proportion to the congressional district. Then all the census block rates in the congressional district were summed to get the final congressional district COVID-19 case rate. Essentially, the county's rate is distributed to the congressional district via the census block using the block embedded in both target zones, and then the estimated rate is the output by aggregating proportionalized rates.

Congressional district affiliation was measured using 2020 House of Representative election data, which allowed for a moving variable to measure the partisan index of congressional districts. The winning representative's vote count was taken as a percentage of the total number of votes in that certain congressional district. Then, the percentage was subtracted from 50 percent so get the political index. For example, a district with an equal number of democratic and republican votes would have an affiliation of zero. So, the primary independent variable was the congressional district vote share. In congressional districts where the democratic candidate won, the affiliation was negated because democrats are traditionally considered left leaning. The districts in which republican candidates won were kept positive because they are considered right leaning. Affiliation was measured very straightforwardly because there are no current third-party representatives in the House of Representatives in the 117th United States Congress. So, only the two major parties, democrat and republican, affiliation was measured. 2018 Midterm Election Results, The Cook Partisan Voter index, and FiveThirtyEight elasticity scores were taken into account to ensure that there were no electoral outliers. For example, candidates who ran unopposed in the congressional elections in 2020 and/or 2018, candidates who faced more than one other major candidate who received or write in votes, or the personality and/or policy of the candidate significantly differ from the political norm which could affect the results of an election. The extent of political affiliation was labeled as the political index.

The confounding variables included the congressional district's population, median household income, population above the age of 65 , population living below the federal poverty line, population with no health insurance coverage, and population density (number of people per square mile). All datasets for the confounding variables came from the United States Government Census website. The confounding variables were weighted according to population or countrywide averages, so that political affiliation would still be the main independent variable.

A linear regression model was used to model the relationship between the two main variables, political affiliation and COVID-19 cases, and the confounding variables as well. Since there were more than two variables, it was a multiple linear regression. The confounding variables were scaled for population, so that they would not be the main independent variables, rather they would be confounders to make a more accurate model. A paired T-test was conducted to compare two population means where there are two samples in which observations in both can be paired. In this case it would be 2 weeks before and after observations.

\section{- Results and Discussion Understanding the Figures:}

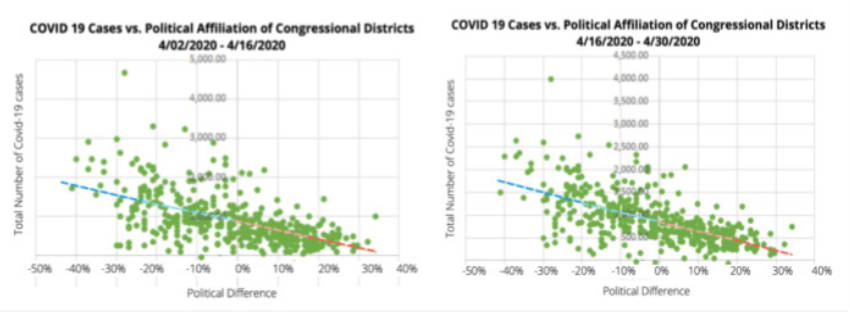

Figure 1: Regression analysis for COVID-19 cases and political affiliation for two weeks before and after April 16, 2020.

In Figure 1, the figure visualizing COVD-19 cases and political index, with confounding variables considered, for the dates of April 2, 2020 to April 16, 2020 has a slope of -2204.7. For the figure graphing out cases between April 16, 2020 and April 30, 2020, the slope is -2152.5 . Both graphs have a decreasing slope, which shows that left leaning districts had a higher case rate when compared with right leaning districts.
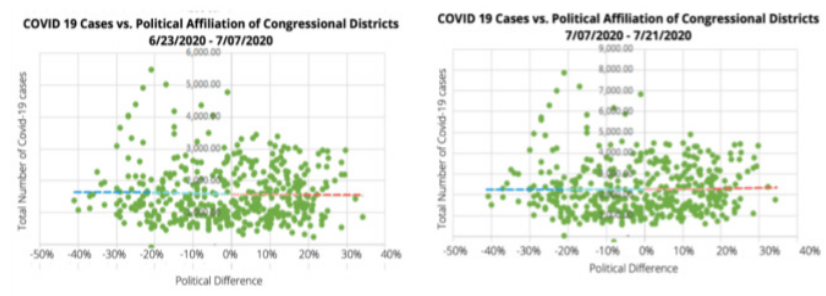

Figure 2: Regression analysis for COVID-19 cases and political affiliation for two weeks before and after July 7, 2021.

In Figure 2, the figure visualizing COVID-19 cases and political index, with confounding variables considered, for the dates of June 23, 2020, to July 7, 2020 has a slope of -125.3 . 
For the figure graphing out cases between July 7, 2020 and July 21, 2020, the slope is 115.9 . The graphs change from decreasing slope to an increase in slope, which shows that right leaning districts saw more of an increase in cases than left leaning districts.
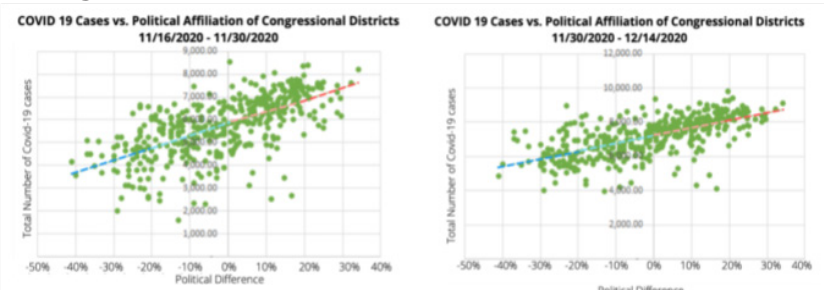

Figure 3: Regression analysis for COVID-19 cases and political affiliation for two weeks before and after November 30, 2020.

In Figure 3, the figure visualizing COVID-19 cases and political index, with confounding variables considered, for the dates of November 16, 2020 to November 30, 2020 has a slope of 5300.2. For the figure graphing out cases between November 30, 2020 and December 14, 2020, the slope is 4530.4. Both graphs have an increasing slope, which shows that right leaning districts had a higher case rate when compared with left leaning districts.
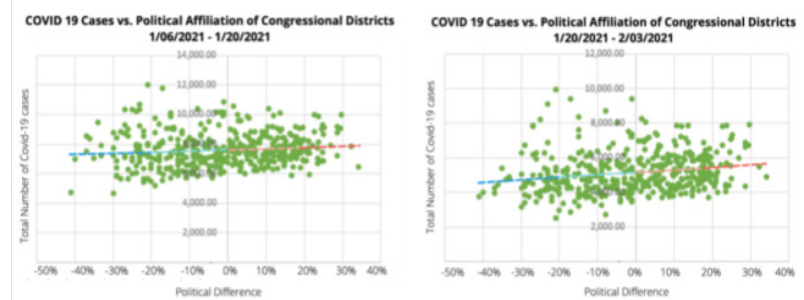

Figure 4: Regression analysis for COVID-19 cases and political affiliation for two weeks before and after January 20, 2021.

In Figure 4, the figure visualizing COVID-19 cases and political index, with confounding variables considered, for the dates of January 6, 2021 to January 20, 2021 has a slope of 783.8. For the figure graphing out cases between January 20, 2021 and February 3, 2021, the slope is 1430.1. There is a significant increase in slope from the first to second graph, which shows that right leaning districts saw more of an increase in cases than left leaning districts.

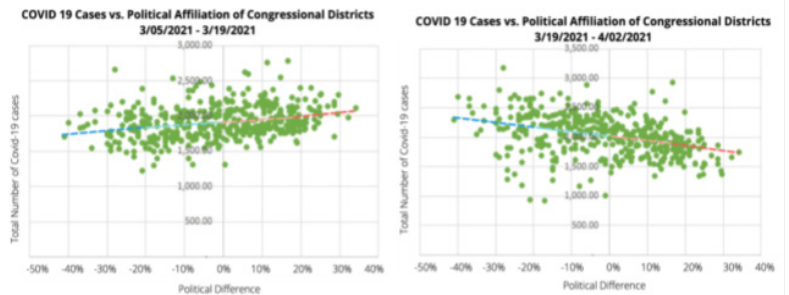

Figure 5: Regression analysis for COVID-19 cases and political affiliation for two weeks before and after March 19, 2021.

In Figure 5, the figure visualizing COVID-19 cases and political index, with confounding variables considered, for the dates of March 5,2021 to March 19,2021 has a slope of 438.8. For the figure graphing out cases between March 19, 2021 and April 2, 2021, the slope is -817.7 . The graphs change from increasing to decreasing, which shows that left leaning districts saw more of an increase in cases than right leaning districts.

Left leaning districts had a higher case count towards the beginning of the pandemic in the month of April as shown by the negative trendline (shown in Figure 1). Left leaning districts could have had a higher case rate towards the beginning of the pandemic due to lack of information or resources. There were less prevention measures that were recommended by the government to the general public. For example, face masks were not recommended until April, which could be the reason behind why left leaning districts had a higher case rate towards the very beginning of the pandemic. However, as more restrictions and guidelines were put in place, there was a shift in the number of cases in right and left leaning districts. Another reason that left-leaning districts saw more of an improvement in the number of cases could be because they hit a ceiling of cases early. By the date of July 07, 2020, COVID-19 cases did not have a significantly positive or negative trend when compared with congressional district political affiliation (shown in Figure 2). It can be inferred that right leaning districts did not respond to the significance of the date when compared to left leaning districts because the change of rate in the slope increased from the two weeks before to the two weeks after. The date of November 30, 2020 shows that right leaning districts had a higher number of cases. It can be presumed that right leaning districts did not heed to the advice of government agencies such as the CDC, when compared to left leaning districts. As mentioned before there was an abundance of guidance and policies from the government in the fall months, especially against traveling during the holidays. However, the slope does decrease in the two weeks after the date, so all political affiliations responded more to the date of November 30, 2020 (shown in Figure 3). The date of January 20, 2021 showed right leaning districts still having higher case rate. However, the slope decreased when compared to the $\mathrm{No}^{-}$ vember date. In the two weeks after the inauguration, there was an increase in slope when compared to two weeks before which shows that right leaning districts responded less to this date. Although, overall, the number of cases decreased significantly for all political affiliations (shown in Figure 4). It can be inferred that the change in political party of the executive branch did show a decrease in COVID-19 cases, which could be because of the policies implemented. The date of March 19, 2021 showed right leaning districts having higher case rate in the two weeks before and left leaning districts having a higher case rate in the two weeks after. Since this date was a milestone for the number of vaccines administered, one of the reasons left leaning districts had a higher case rate could be vaccine disparity. At this point in time there was no complete vaccine roll out by the government. Certain groups did not have the resources or access to be able to get a vaccine at that point in time, which could explain the inverse change in slopes (shown in Figure 5). The percent change formula was used to calculate the difference in slopes and see how right and left leaning districts responded to the significant date. The date of April 16, 2020 had a percent change, from two weeks before to two after, of $2.5 \%$. The date of June 7, 2020 had a percent change 
of $190 \%$. The date of November 30, 2020 had a percent change of $14.5 \%$. The date of January 20, 2021 had a percent change of $82 \%$. The date of March 19, 2021 had a percent change of $286 \%$. From this data it can be concluded that the change in the number of cases in regard to congressional district affiliation did not particularly sway one way or the other. However, the data also suggests that right leaning districts responded less because the percent changes are higher and lean more positive, which are the $\mathrm{x}$-values representing right leaning districts.

\section{Understanding the Tables:}

Table 1: Regression analysis, Pearson correlation, and paired t-test results for April 16, 2020.

\begin{tabular}{|l|r|r|} 
& $4 / 16 / 2020$ & $4 / 30 / 2020$ \\
\hline Mean & 888.656 & 896.059059 \\
\hline Variance & 412231.9665 & 294044.704 \\
\hline $\begin{array}{l}\text { Pearson } \\
\text { Correlation }\end{array}$ & 0.977125557 & \\
\hline $\begin{array}{l}\text { Hypothesized } \\
\text { Mean } \\
\text { Difference }\end{array}$ & 0 & \\
\hline t Stat & -0.948564889 & \\
\hline $\begin{array}{l}\text { P(T<=t) } \\
\text { two-tail }\end{array}$ & 0.343382278 & \\
\hline & & \\
\hline $\begin{array}{l}\text { t Critical } \\
\text { two-tail }\end{array}$ & 1.965574698 & \\
\hline
\end{tabular}

Table 1 shows the results for the paired t-test and regression analysis, with the two different groups being the two weeks before April 16, 2020 and the two weeks after. The t-statistic is around -0.949 and the $t$ critical value is around 1.966 . The Pearson correlation coefficient is around 0.977.

Table 2: Regression analysis, Pearson correlation, and paired t-test results for July 7,2020 .

\begin{tabular}{|l|r|c|}
\hline & $\begin{array}{c}\text { 6/23/2020- } \\
7 / 07 / 2020\end{array}$ & $\begin{array}{c}7 / 07 / 2020- \\
7 / 21 / 2020\end{array}$ \\
\hline Mean & 1595.656941 & 2272.4418 \\
\hline Variance & 763544.1845 & 1525026.7 \\
\hline $\begin{array}{l}\text { Pearson } \\
\text { Correlation }\end{array}$ & 0.991503208 & \\
\hline $\begin{array}{l}\text { Hypothesized } \\
\text { Mean } \\
\text { Difference }\end{array}$ & & \\
\hline t Stat & 0 & \\
\hline P(T<=t) two-tail & $1.09 \mathrm{E}-131$ & \\
\hline t Critical two-tail & 1.965574698 & \\
\hline
\end{tabular}

Table 2 shows the results for the paired t-test and regression analysis, with the two different groups being the two weeks before July 7, 2020 and the two weeks after. The t-statistic is around -36.177 and the $t$ critical value is around 1.966 . The Pearson correlation coefficient is around 0.992.
Table 3: Regression analysis, Pearson correlation, and paired t-test results for November 30, 2020

\begin{tabular}{|l|r|r|}
\hline Mean & $\begin{array}{c}11 / 16 / 2020- \\
11 / 30 / 2020\end{array}$ & $\begin{array}{c}11 / 30 / 2020- \\
12 / 14 / 2020\end{array}$ \\
\hline Variance & 1655141.072 & 1222659 \\
\hline $\begin{array}{l}\text { Pearson } \\
\text { Correlation }\end{array}$ & 0.931062593 & \\
\hline $\begin{array}{l}\text { Hypothesized } \\
\text { Mean } \\
\text { Difference }\end{array}$ & & \\
\hline Stat & 0 & \\
\hline St & & \\
\hline (T< $t)$ two-tail & $3.52 \mathrm{E}-212$ & \\
\hline$t$ Critical two-tail & 1.965574698 & \\
\hline
\end{tabular}

Table 3 shows the results for the paired t-test and regression analysis, with the two different groups being the two weeks before November 30, 2020 and the two weeks after. The t-statistic is around -61.056 and the $t$ critical value is around 1.966 . The Pearson correlation coefficient is around 0.931.

Table 4: Regression analysis, Pearson correlation, and paired t-test results for January 20, 2021

\begin{tabular}{|l|r|r|}
\hline & $\begin{array}{c}1 / 06 / 2021- \\
1 / 20 / 2021\end{array}$ & $\begin{array}{c}1 / 20 / 2021- \\
2 / 03 / 2021\end{array}$ \\
\hline Mean & 7620.076706 & 5166.212235 \\
\hline Variance & 1298856.076 & 1370160.661 \\
\hline $\begin{array}{l}\text { Pearson } \\
\text { Correlation }\end{array}$ & 0.887853353 & \\
\hline $\begin{array}{l}\text { Hypothesized } \\
\text { Mean } \\
\text { Difference }\end{array}$ & & \\
\hline Stat & 92.33439381 & \\
\hline & & \\
\hline P(T<=t) two-tail & $6.57 \mathrm{E}-283$ & \\
\hline & & \\
\hline & & \\
\hline
\end{tabular}

Table 4 shows the results for the paired t-test and regression analysis, with the two different groups being the two weeks before January 20, 2021 and the two weeks after. The t-statistic is around 92.334 and the $t$ critical value is around 1.966 . The Pearson correlation coefficient is around 0.888 .

Table 5: Regression analysis, Pearson correlation, and paired t-test results for March 19, 2021

\begin{tabular}{|l|r|r|}
\hline & $\begin{array}{r}3 / 05 / 2021- \\
3 / 19 / 2021\end{array}$ & $\begin{array}{c}3 / 19 / 2021- \\
4 / 02 / 2021\end{array}$ \\
\hline Mean & 1914.674353 & 2027.7471 \\
\hline Variance & 55337.11838 & 113704.01 \\
\hline $\begin{array}{l}\text { Pearson } \\
\text { Correlation }\end{array}$ & 0.062301914 & \\
\hline $\begin{array}{l}\text { Hypothesized } \\
\text { Mean } \\
\text { Difference }\end{array}$ & & \\
\hline \begin{tabular}{l}
$t$ Stat \\
\hline $\begin{array}{l}\text { P(T<=t) } \\
\text { two-tail }\end{array}$
\end{tabular} & -5.84304249 & \\
\hline $\begin{array}{l}t \text { Critical } \\
\text { two-tail }\end{array}$ & $1.02 \mathrm{~T}-08$ & \\
\hline
\end{tabular}

Table 1 shows the results for the paired t-test and regression analysis, with the two different groups being the two weeks before March 19, 2021 and the two weeks after. The t-statistic 
is around -5.843 and the $t$ critical value is around 1.966 . The Pearson correlation coefficient is around 0.062 .

When running a paired $t$-test, having a $t$-statistic greater than the $t$-critical value means that there is a significant difference in the data. The date of April 16, 2020 did not have a significant impact on COVID-19 cases because of a lesser t-value (Table 1). This was still very early in the pandemic where there was not a lot of information available, which could explain why April 16, 2020 did not affect the public's actions and infection rates. July 7, 2020 did have a greater t-value, so it did have a significant impact on COVID-19 cases (Table 2). Overall, there was less of a response to the date, for example the number of cases increased by less than two percent, but it still impacted the number of cases. November 30, 2020 had an incredibly high $\mathrm{t}$-value, so it did have a significant impact on the number of cases (Table 3). This again shows the effect the holiday time had on the pandemic. January 20, 2021 also had a high $\mathrm{t}$-value, so it did have an impact on the number of cases. This shows that the inauguration could have had an impact on the number of COVID-19 cases. Lastly, the date of March 19, 2021 also had a $t$ statistic greater than the critical value, which shows that the date was significant. This supports the idea that the number of vaccines administered significantly impacted the COVID-19 case rate. There are other factors that could have influenced the data, but these conclusions can be made from looking at the significance of date.

\section{The Effect of Confounding Variables:}

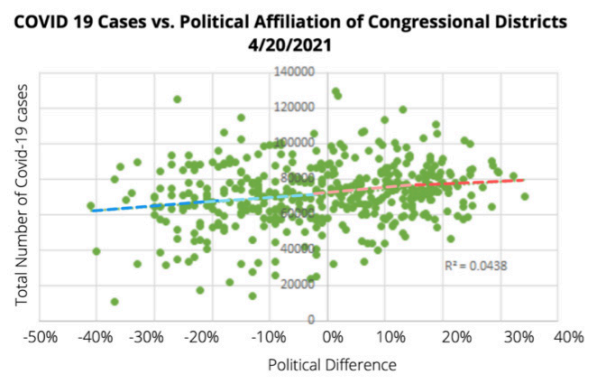

Figure 6: Regression analysis for COVID-19 cases and political affiliation from the beginning of the pandemic to April 20,2021, but without the inclusion of confounding variables.

Figure 6 shows the graph of the total number of COVID-19 cases and political index, with no confounding variables considered. It has an $\mathrm{R} 2$ value of 0.0438 .

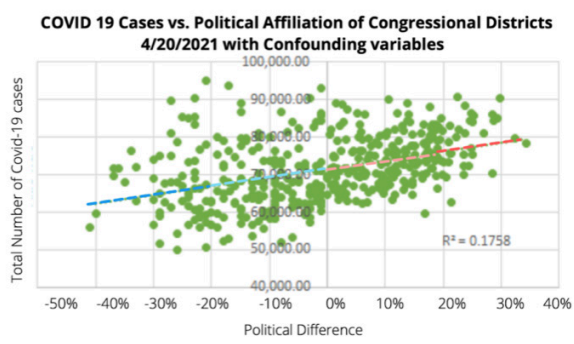

Figure 7: Regression analysis for COVID-19 cases and political affiliation from the beginning of the pandemic to April 20, 2021, but without the inclusion of confounding variables.

The data without confounding variables had a wider variance associated with it, when compared to the data that have confounding variables to cause a spurious association. The data points are much more spread out; however, it does not alter the trendline of the data to a great extent (as shown in Figure 6 and 7). The $\mathrm{R} 2$ value for the data without confounding variables is 0.0438 as seen in Figure 6, and the R2 value for the data with confounding variables is 0.1758 as seen in Figure 7. Since this research is based on human behavior, the $\mathrm{R} 2$ value is closer to zero, however it can be interpreted that the data with confounding variables has less variance and therefore is a better fit to the regression line when compared to the data without confounding variables because it has a higher $\mathrm{R} 2$ value. This confirms that the confounding variables - congressional district's population, median household income, population above the age of 65 , population living below the federal poverty line, population with no health insurance coverage, and population density - had an influence on both political affiliation and the number of COVID-19 confirmed cases. Adding confounders strengthened the applicability of the data, and helps researchers understand the distinct relationship between COVID-19 cases and political affiliation.

\section{Interpreting the Conclusions:}

Many of these conclusions support the validity of many statements heard on the news and the internet. There are polls and data that have found that right leaning individuals do not follow government suggested health policies as well as left leaning individuals do. There is also an innate difference in these groups as they perceive the virus in different ways. One reason for this is that the right leaning media has facilitated the spread of misinformation from the early stages of the pandemic. Polling has found that only 38 percent of Fox News viewers, a right-wing media outlet, are worried about the virus compared to over 70 percent of CNN viewers, a left-wing media outlet. Right leaning media was also more likely to make inaccurate claims about the treatment of COVID-19. Although, it is hard to specify who exactly consumed these types of media, it can be inferred that right leaning individuals consumed right leaning media. (Motta et al. 2020). ${ }^{10}$ As mentioned previously, right leaning districts did not follow public health measures, such as social distancing, as well as left leaning districts, which could have led to them having a higher number of COVID-19 cases (Gollwitzer et al. 2020). ${ }^{1}$ Right leaning individuals are less likely to wear masks because they don't feel as threatened by the virus itself (Nowlan et al. 2020). ${ }^{11}$ This could explain why there is less of a response from right leaning districts to those specific dates. The data, taken together, suggests that right leaning districts had a higher number of cases throughout the pandemic, and they also responded to policies and significant days of the pandemic much less.

\section{Conclusion}

A paired t-test supported that most of the dates did have a significance in affecting the COVID-19 case rate, and that right leaning districts responded less to those critical dates compared to left leaning districts. Specifically, the dates of July 14, 2020, November 30, 2020, January 20, 2021, and March 19, 2021 had a significance in affecting COVID-19 cases, while the date of April 16, 2020 did not have a significant impact on the case rate. Based on the data, left leaning districts had a 
higher case rate towards the very beginning of the pandemic, however right leaning districts saw a larger increase in cases overall. Right leaning districts had less of a response to the significant dates and saw a significantly greater increase as there was an increase in time and an increase in information. In the future, this model could help predict how certain politically affiliated groups act and respond during health outbreaks and which groups have a higher chance of being infected.

Future research could include adding other confounding variables, for example the presence of racial minorities, availability of resources to protect themselves from the virus because they have an effect on the COVID-19 case rate. Furthermore, future research could include considering time series methods and controlling for existing or cumulative cases, and it could also explicitly account for the spillover of cases across adjacent congressional districts.

Another source of error that needs to be implemented in the future is vaccine numbers and disparities. Some districts have more availability to obtain the vaccine and it could be another confounding factor that could affect the COVID-19 case rate more recently because of the high vaccination rates throughout the country. Overall, it can be interpreted from the data that right leaning districts responded less to the COVID-19 prevention measures placed when compared to left leaning districts. The fact that left-leaning districts initially had higher case rates instead of comparable case rates to right-leaning districts makes the shift over time even more marked.

\section{Acknowledgements}

I would like to thank my research teacher, Mr. Proffitt. He provided guidance throughout the research process, and I am so grateful for him. I would also like to thank the Academy of Science for giving me the opportunity and resources to conduct my research project.

\section{- References}

1. Gollwitzer, A., Martel, C., Brady, W.J. Paernamets, P., Freedman, I,G, Knowles, E.D., Van Bavel, J. J. Partisan differences in physical distancing are linked to health outcomes during the COVID-19 pandemic. Nat Hum Behav 4, 1186-1197 (2020). https://doi. org/10.1038/s41562-020-00977-7

2. NBC Nerws/Wall Street Journal Survey Datasets (Hart Research Associates/Public Opinion Strategies, 2020); https://www.documentcloud.org/documents/6810602-200149NBCWSJ-March-Poll-Final-3-120-Release.html

3. Bird, R. \& Ritter, Z. Is the media creating division on COVID-19 health practices? Gallup https://news.gallup.com/poll/312749/ media-creating-division-covid-health-practices.asp (2020).

4. Congressional District. https://www.merriam-webster. $\mathrm{com} /$ dictionary/congressional district.

5. Neelon, B., Mutiso, F., Mueller, N. T., Pearce, J. L., \& BenjaminNeelon, S. E. (2020). Associations between governor political affiliation and COVID-19 cases and deaths in the United States. medRxiv: the preprint server for health sciences, 2020.10.08.20209619. https://doi.org/10.1101/2020.10.08.20209619

6. DeSouza PN, Subramanian SV. COVID-19 across United States congressional districts.J GlobHealth Sci. 2020;2:e22. https://doi. org/10.35500/jghs.2020.2.e22

7. Johnson, K., Khayyat-Kholghi, M., Johnson B., Tereshchenko, L. (2020). The Association Between the Rate of AngiotensinConverting Enzyme Inhibitors and Angiotensin Receptor
Blockers Use and The Number of Covid-19 Confirmed

Cases and Deaths in the United States: Geospatial

Study. medRxiv, 2020.05.31.20118802.

https://doi.org/10.1101/2020.05.31.20118802

8. Wang, H., \& Yang, J. (2016). Multiple Confounders Correction with Regularized Linear Mixed Effect Models, with Application in Biological Processes. BioRxiv, 14, 9. https://doi.org/10.1101/089052

9. Wei, J. (2021). Analyzing the Relation Between Government AntiContagion Policy Severity and United States COVID-19 Epidemiological Data.

10.Motta, M., Stecula, D., \& Farhart, C. (2020). How RightLeaning Media Coverage of COVID-19 Facilitated the Spread of Misinformation in the Early Stages of the Pandemic in the U.S. Canadian Journal of Political Science, 53(2), 335-342. doi:10.1017/S0008423920000396

11.Nowlan, L., Zane, D (2020). Getting Conservatives and Liberals to Agree on the COVID-19 Threat. Journal of the Association for Consumer Research, 2020; https://doi.org/10.1086/711838

\section{- Author}

Divya Kumar is a junior at Freedom High School and The Academy of Science, where she is a student researcher. She loves doing research and enjoys learning about social sciences. She hopes to major in public policy in the future. 